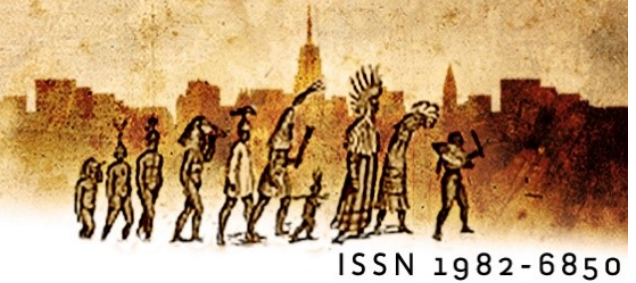

\title{
A importância das edições independentes para as últimas publicações de Augusto de Campos
}

Raquel Campos ${ }^{\mathrm{i}}$

\begin{abstract}
Resumo: O poeta Augusto de Campos teve seus poemas publicados, no início da década de 1950, por meio de editoras independentes, com edições geralmente financiadas pelo próprio autor. Seu vínculo com editoras menores, portanto, se estabeleceu há quase 70 anos atrás e continua, até hoje, sendo importante para sua obra. Ainda que Augusto conte com um reconhecimento nacional e internacional de seu trabalho e tenha sido, inclusive, publicado por grandes editoras brasileiras, ele permanece sendo publicado de maneira independente ou por meio de sites e revistas online, e de suas próprias redes sociais. Há aproximadamente dois anos, Augusto de Campos lançou diversas traduções e uma entrevista pela Galileu Edições, editora independente, criada por Jardel Cavalcanti. O presente trabalho retrata essa dualidade entre a repercussão e a relevância de sua obra e as publicações feitas por editoras menores e pelos meios digitais, explorando os possíveis motivos para que isso tenha ocorrido. Além disso, é dado destaque, no artigo, aos livros lançados pela Galileu Edições, assim como aos poemas inéditos divulgados nas redes sociais do poeta, que, mesmo com seus 90 anos, se adaptou às tecnologias mais recentes e segue se colocando a favor de uma poesia marginalizada, experimental e inventiva.
\end{abstract}

Palavras-chave: Augusto de Campos; edições independentes; concretismo.

A verdade é que a poesia dá provas de ainda resistir, nas mais diversas formas, como um respiradouro contestatário à linguagem contratual e decretal, e, mesmo em suas variantes de baixo repertório, parece achar formas de corroer o tecido conservador que tenta dominar a liberdade e a evolução do ser humano.

Augusto de Campos

Augusto de Campos é, para parte da crítica literária brasileira, um autor consolidado, cuja obra não participa do que se entende, no geral, como uma literatura 
independente. O poeta já teve obras publicadas por grandes editoras, nacional e internacionalmente. No entanto, seus últimos livros lançados se aproximam das primeiras publicações do início de sua vida literária, na década de 1950: foram lançados através de edições independentes, com tiragem limitada e financiados pelo próprio autor ou por editores amigos e apoiadores de sua poesia.

Por não apenas defenderem, mas terem criado um novo tipo de poesia - a poesia concreta - Augusto de Campos, junto a Haroldo de Campos, seu irmão, e Décio Pignatari, foram marginalizados pela crítica literária e pelos espaços acadêmicos. Parte dessa recepção ao movimento concretista ocorre até hoje, como ressalta o colunista Manuel da Costa Pinto, ao noticiar o lançamento do livro Poesia Concreta Brasileira - As Vanguardas na Encruzilhada Modernista (2005), de Gonzalo Aguilar: "é a primeira leitura sistemática do último movimento vanguardista surgido no Brasil. E o fato de ter sido escrito pelo argentino Gonzalo Aguilar demonstra até que ponto a recepção do concretismo ainda é um buraco negro da crítica" (PINTO, 2005).

Os espaços nos veículos de comunicação, portanto, ainda são restritos e a divulgação de seus novos livros pequena ou inexistente. Em 2017, por exemplo, Augusto recebeu o prestigiado prêmio de poesia Jannus Pannonius Grand Prize for Poetry em Pécs, cidade húngara onde a premiação aconteceu e nenhum jornal brasileiro da grande mídia noticiou o evento, que poderia ser considerado como uma celebração da poesia brasileira experimental e de invenção. Há, portanto, a respeito de Augusto, sempre essa dualidade entre o reconhecimento internacional e a luta por reconhecimento dentro do próprio país.

\section{Espaços virtuais}

O que tem, no entanto, ajudado e sido um fator determinante para que a obra de Augusto continue a circular e seja divulgada com frequência é a Internet e, mais recentemente, as redes sociais. Adepto, desde o surgimento dos primeiros computadores no Brasil, ao uso da tecnologia para a criação poética - Augusto especialmente, em relação aos outros fundadores do concretismo, deu vazão ao verbivocovisual de sua poesia através das inúmeras possibilidades do espaço virtual - o 
poeta explora a potencialidade do universo da Internet para publicar textos teóricos, artigos, entrevistas e também poemas inéditos.

Há uma nova presença entre os poetas do Instagram. Desde março deste ano, Augusto de Campos tem uma conta (@poetamenos) em que posta não só material antigo, mas também, de forma surpreendente, vários poemas inéditos. Pensando bem, não se trata de algo tão surpreendente, já que Augusto é precursor quando o assunto é a relação entre texto e novos suportes, sobretudo eletrônicos e digitais. Se seu trabalho desde os anos 1950 já entendia a poesia em movimento no livro ou fora dele, é a partir dos anos 1970, com a presença da computação, que a coisa deslancha até chegar aos clip-poemas. O que surpreende agora talvez seja a velocidade com que tais inéditos têm aparecido, produzidos no ritmo dos acontecimentos recentes do país. Espantoso para um poeta que costuma publicar poesia de forma tão espaçada. (GANDOLFI, 2018)

Auxiliado por membros da família, Augusto, aos 90 anos, reivindica para si, portanto, estes novos espaços online, em que não há restrição ou censura quanto ao conteúdo do que publica ou limitação quanto à frequência das publicações. Redes sociais como o Instagram e o Facebook e plataformas digitais como o Youtube têm sido importantes novos aliados na divulgação de sua obra e no diálogo com seus leitores. Muitos de seus poemas inéditos têm surgido como resposta a acontecimentos políticos no país, desde a prisão do ex-presidente Lula até a eleição de Bolsonaro e os dias atuais, imersos em meio à crise do coronavírus.

A poesia publicada "espaçadamente", como dito na citação acima, foi quebrada através da publicação pontual de poemas isolados. Esta "resposta" de Augusto (que ele chama de "contrapoema") a acontecimentos políticos no país e sua crítica ferrenha a respeito da conduta de parte da mídia resultam em poemas como "ERRAMOS!", publicado, pelo Instagram, em dezembro de 2018, no mesmo dia em que uma manchete do jornal Folha de S.Paulo dizia: "otimismo com economia dispara". O contrapoema irônico, veio, então, logo em seguida, escrito em verde e amarelo sob um fundo azul: "otimismo com a economia do nosso país diz: para!!!!". São contrapoemas, extraduções e recriações: poemas atuando enquanto ready-mades artísticos e pontuais, reagindo aos absurdos do mundo por meio da linguagem criativa e tecnológica da poesia. 
Em seu livro de poemas Outro, publicado, em 2015, Augusto afirma, no prefácio outronão, que "há 60 anos, ao compor os poemas em cores do ciclo POETAMENOS, penosamente datilografados em folhas dobradas, com interpostos carbonos de várias cores, eu clamava por luminosos ou filmletras" (CAMPOS, 2015, p.9). Cita logo depois, Mallarmé, que, com seu poema $O$ lance de dados, mudou a trajetória da poesia no mundo inteiro, e Walter Benjamin que previu, em 1926, em seu texto "Revisor de livros juramentado" que no futuro, antes mesmo de se abrir um livro, o leitor se depararia com letras móveis e cores, diminuindo as possibilidades do livro ao passo que aumentando as chances produzidas pelas novas tecnologias.

Ainda com Augusto: "não posso me queixar. O mundo digital colocou tudo isso ao alcance dos meus dedos. (...) Os erros ou ineficiências são todos mea culpa. E a única justificativa que posso dar é a de ter chegado muito tarde a um mundo muito novo" (ibidem). Ainda que tenha chegado tarde, Augusto permanece, desde a década de 1950, com a série Poetamenos, utilizando as inovações tecnológicas para expandir as possibilidades poéticas verbivocovisuais e, com a chegada dos computadores no Brasil, as utiliza para além do espaço da página, contando com o movimento e o dinamismo das cores, dos sons e dos vídeos.

\section{Poesia concreta e seu salto participante}

O caráter independente das obras de um poeta reconhecido internacionalmente pode ser atribuído a alguns fatores, entre eles, políticos. Augusto se posicionou, ao longo de sua carreira, politicamente, em especial após o "salto participante" dado pela poesia concreta na década de 1960, perante a ditadura que se consolidava no Brasil. O movimento concretista, criado oficialmente em 1956, junto a Haroldo de Campos, seu irmão, e a Décio Pignatari, teve um impacto revolucionário desde o início e foi considerado pela crítica como o "rock'n'roll da poesia" - os três foram até mesmo acusados de quererem "mudar a maneira de ler e escrever"

\footnotetext{
${ }^{1}$ Citações retiradas do livro À margem da margem (1989), de Augusto de Campos. O poeta reuniu numa página intitulada The Gentle Art of Making Enemies ("A gentil arte de fazer inimigos") as principais manchetes publicadas na época do surgimento do concretismo no Brasil.
} 
De fato, queriam (apenas em se tratando de poesia, é bom ressaltar), mas não do modo como a crítica sugeriu, com seu desdém pela poesia de vanguarda. Além disso, a acusação de que "mataram a poesia" ${ }^{2}$ exemplifica a reação inicial quanto à poesia concreta e que apresenta suas reverberações até hoje, seja por meio da falta de reconhecimento da importância deste movimento nacional ou mesmo pelo silêncio destinado a Augusto, que, hoje com 89 anos, ainda produz e publica poemas inéditos e segue como o maior representante vivo do concretismo (e de toda a sua poesia feita para além dele, com suas traduções criativas e com o resgate de poetas e escritores obscurecidos pela crítica e pela academia, como Oswald de Andrade, Sousândrade e Pagu, cuja biografia escrita por Augusto teve sua primeira edição em 1982).

A respeito do "silêncio" da grande mídia em relação a Augusto (quebrado, eventualmente, por algumas exceções), pode-se dizer que este passa por uma série de questões não apenas poéticas como também políticas. As polêmicas com outros poetas, como a já conhecida controvérsia entre ele e Ferreira Gullar, e os embates com a postura de certos veículos de comunicação foram travados, além de tudo, no campo político, marcando e reafirmando, ao longo de mais de cinco décadas, seu posicionamento de esquerda.

Augusto de Campos, Haroldo de Campos e Décio Pignatari se envolveram politicamente ao longo da vida, não apenas por meio de entrevistas concedidas mas também através de suas obras, individuais e coletivas. Podemos exemplificar tal envolvimento com poemas marcantes da década de 1960, que dizem respeito ao "salto participante" da poesia concreta (denominação dada por Décio Pignatari), i.e., uma poesia mais explicitamente política, a exemplo do poeta russo Vladimir Maiakovski, que dizia não haver arte revolucionária sem forma revolucionária. Assim, sem deixar de levar em conta a estrutura dos poemas, eles aliaram forma a conteúdo para contestar o cenário político nacional.

"Cubagrama", de Augusto, foi lançado em 1962, em meio à efervescência da Revolução Cubana. O poema, com suas letras vermelhas e maiúsculas, nos dizia "CUBA SIM IANQUE NÃO", entre outros versos espalhados pela página. Já em "Servidão de Passagem", publicado em 1961, Haroldo escrevia sobre a "poesia em

\footnotetext{
${ }^{2}$ Citação também retirada de À margem da margem (1989).
} 
tempo de fome/fome em tempo de poesia", enfatizando a desigualdade social e a exploração humana capitalista e Décio publica, neste mesmo período, sua "Estela cubana", evidenciando, dessa forma, a participação política através dos poemas dos três fundadores do concretismo.

Em entrevista ao Jornal da Unicamp, em 2008, Augusto comenta sobre os poemas dessa época e sobre o risco que correram com as publicações contrárias à ditadura a partir da década de 1960:

Nunca pertenci ao "Partidão", e desde sempre detestei Stálin e Jdânov, mas a ditadura militar me indignava, e eu provocava. Em 1962, eu tinha publicado o suspeito "Greve" e o explícito "Cubagrama". Em dezembro de 64, havia exposto na Galeria Atrium, Avenida São Luiz, no centro de São Paulo, os meus "popcretos", entre os quais "Olho por Olho" e "SS", que denunciavam e satirizavam o golpe militar. Mais ainda: em setembro do mesmo ano, no famoso Times Literary Supplement de Londres, saíra o não menos satírico "Brazilian Football" (jogando com as palavras GOAL e GAOL (variante de "Jail"). Eu não tinha defesa, caso os milicos lessem poesia ou os mais famosos jornais literários do mundo. Não liam, apesar de estarem de olho no Ênio Silveira. Com o apoio pardo-eminente do suposto "gênio" letrado Golbery (como é que não entrou na Academia Brasileira de Letras?) estavam preocupados só com o grande público da televisão e dos festivais de música popular. Mesmo assim, ficávamos à mercê de algum dedo-duro. Por sorte não aconteceu, salvo incidentes menores. (CAMPOS, 2008)

Os posicionamentos políticos de Augusto marcaram sua obra e, como o poeta criticou explicitamente os principais meios de comunicação por conta do tratamento midiático dado ao Golpe de 2016 e à eleição presidencial de 2018, alguns espaços para publicação foram reduzidos. Isso tudo se junta à crise do mercado editorial de 2018, em que as dificuldades para publicação se tornaram mais evidentes e inviabilizaram alguns lançamentos previstos. Porém, atualmente, além dos espaços propiciados pelas redes sociais, Augusto lança, desde 2018, pequenas tiragens de livros publicados pelas Galileu Edições, cujo editor é o historiador e poeta Jardel Dias Cavalcanti. Isso foi importante pois permitiu que a produção do autor continuasse a ser divulgada, e que suas traduções inéditas fossem publicadas.

\section{Galileu Edições}

Até o final dos anos 1970, as publicações de livros de poemas de Augusto de Campos foram todas independentes - financiadas por ele e/ou por terceiros - ou Eutomia, Recife, 28(1): 7-21, Dez. 2020 
então seus poemas e textos foram publicados em jornais como O Estado de S.Paulo e o Jornal do Brasil e, especialmente, pela Revista Noigandres (organizada e lançada pelo grupo - um importante marco do concretismo brasileiro, na década de 1950-60).

A poesia concreta foi aos poucos, portanto, conquistando o seu espaço no meio editorial e nos veículos de comunicação. Durante a trajetória editorial de cada um dos fundadores do movimento concretista, no entanto, houve sempre uma alternância entre livros lançados por editoras de grande alcance nacional e outros projetos publicados de maneira independente ou por editoras menores.

Quanto às obras de Augusto de Campos, podemos citar algumas edições criadas e financiadas pelo próprio autor, como a Caixa Preta (1975), com seus objetos-poemas em colaboração com Julio Plaza, o poema Não (1990), antes da publicação do livro homônimo, este poema foi lançado por Augusto. Além disso, vale mencionar os lançamentos feitos pela Editora Noa Noa, uma editora independente criada pelo poeta Cleber Teixeira em 1965 ("Não foi Augusto de Campos quem chamou Cleber Teixeira de poeta da edição?"3) e o Selo Demônio Negro, criado por Vanderley Mendonça, que publicou uma nova edição dos Poemóbiles (2010), este livro-objeto feito por Augusto de Campos e Julio Plaza - cuja primeira edição é de 1968 - e, recentemente, uma antologia alemã com poemas de Augusto de Campos traduzidos por Simone Homem de Mello, Poesie - Eine Anthologie (2019).

Muitas das últimas publicações de Augusto têm sido lançadas, no entanto, pela Galileu Edições. O formato adotado consiste em plaquetes com as traduções feitas pelo autor e publicadas em edições bilingues. Segundo entrevista dada a Revista Abraços Morbos, Jardel Cavalcanti afirma que a inspiração por trás da criação da editora foi dar prosseguimento ao trabalho de Ronald Polito (editor da Espectro Editorial), através da publicação das plaquetes com poemas.

Como o trabalho dele preenchia um espaço vazio das editoras que não têm interesse em editar poetas e poesia traduzida (a não ser que sejam poetas midiáticos ou consagrados), senti grande pena em ver esse trabalho se encerrar. Comecei seguindo o seu caminho,

\footnotetext{
${ }^{3}$ VIGNOLI, Flávio. Cleber Teixeira. Disponível em: <http://www.editoranoanoa.com.br/cleber-teixeira/>. Acesso em: 2 jan. 2021.
} 
distribuindo gratuitamente pequenas edições de 30 exemplares para poetas principalmente. $\mathrm{O}$ que faço em parte até hoje, mas também cobrando por algumas edições para não ir à falência. Com a venda, posso publicar poetas que não podem pagar por uma edição e distribuir parte dessa produção de graça. (CAVALCANTI, 2020)

A pouca rentabilidade associada à edição de livros de poesia acaba se tornando um obstáculo para a publicação de jovens poetas e mesmo daqueles já conhecidos e publicados. O mundo virtual auxilia na divulgação de tais poetas e também as editoras menores e independentes, geralmente movidas pela paixão poética e literária e com pouco retorno financeiro. Jardel segue, dessa forma, o trabalho de outros editores antes dele, que tinham a preocupação especificamente com as edições de poesia.

O contato de Jardel com Augusto é de longa data, inclusive uma das plaquetes lançadas em 2019 foi de uma entrevista do poeta paulistano feita por ele no ano 2000 - Entrevista Poesia e Ditadura (2019). O convite para as recentes publicações, no entanto, e o conhecimento de Augusto sobre a Galileu Edições, veio a partir do envio ao poeta de um ensaio do pianista Gleen Gould sobre a obra de Anton Webern, publicado pela editora. A partir de então, estabeleceu-se a parceria entre os dois que, até o momento, já rendeu oito plaquetes.

A respeito das obras de Augusto publicadas pela Galileu Edições, podemos citar, além desta última, a tradução de O Albatroz (2018), de Charles Baudelaire; Retrato de Sylvia Plath como Artista (2018), com seis poemas traduzidos; Latinogramas - Extraduções (2019), com traduções de Ausônio, Catulo, Horácio, Marcial e Propércio; Esses Russos - Extraduções (2019), com traduções de Vladimir Maiakovski e Marina Tsvetaeva, entre outros; Marianne Moore - 10 Poemas (2019); Rimbaud - Extraduções (2019); e, por fim, Poetas Bizarros na Internet - Extraduções (2020), com traduções dos "maneiristas" italianos Luigi Groto e Ludovico Leporeo.

A rapidez dos lançamentos facilita a produção do poeta, além de proporcionar a oportunidade de editar conteúdos menores e talvez mais difíceis de serem aceitos por grandes editoras, como traduções de poetas menos conhecidos ou considerados herméticos. A tiragem também, por conta dos meios digitais, pode ser controlada a partir da demanda dos leitores. Não há o intermédio das livrarias, neste caso, e o 
contato é feito diretamente com o próprio editor, estabelecendo, assim, um diálogo mais direto e informal com o público.

A Galileu Edições chegou inclusive a sair, recentemente, numa matéria de Carlos Adriano, na Folha de S.Paulo, a respeito dos Latinogramas. O texto fala sobre essa plaquete bilingue, com traduções de Augusto dos poetas latinos. O paideuma ${ }^{4}$ criado pelos concretos no Brasil abarca muitos autores de poesia experimental e de vanguarda e, além de tudo, outros até mesmo considerados "clássicos" dentro da literatura canônica. O que importa, afinal, é a estrutura poética, a concreção e a materialidade da palavra e o trabalho com a linguagem (a "operação do texto", como no título do livro de Haroldo de Campos). Adriano entrevista Augusto, para a matéria, e assim o poeta pôde falar mais sobre as edições independentes de tais plaquetes e que pretende reunir (as extraduções todas) futuramente num único livro.

"Extraduções", explica o autor, "é o título de um futuro livro com traduções esparsas, recentes como as de Catulo, e inéditas, como as de Kamiênski e lliazd. Hoje as grandes editoras penam com dificuldades financeiras e minguado apoio institucional; prefiro desonerá-las de prejuízo. Graças a um convite do editor independente Jardel Dias Cavalcanti, pus-me a organizar miniantologias, porque é o que posso fazer, diante das muitas solicitações que recaem sobre um velho poeta, e porque gosto de projetar graficamente os livrinhos", diz Campos. (ADRIANO, 2020)

Como dito acima, Augusto geralmente participa ou mesmo se ocupa inteiramente da diagramação e da parte gráfica do livro. A forma não apenas dos poemas como do livro em si importa para a publicação e Augusto escolhe as cores, fontes, tamanhos e, porventura, imagens que componham o livro. O próprio editor Jardel Cavalcanti afirma, em sua entrevista citada anteriormente, que, "no caso do Augusto de Campos, que tem preocupação absoluta pela forma", costuma receber o livro "praticamente pronto, só adaptando uma coisinha de nada para a impressão sair correta" (CAVALCANTI, 2020).

\footnotetext{
${ }^{4}$ Conceito utilizado pelo poeta Ezra Pound, que designa uma espécie de organização do conhecimento a fim de que a próxima geração o acesse da maneira mais rápida possível. No entanto, diferentemente da tradição canônica, os poetas concretos resolveram resgatar, para o seu paideuma, poetas esquecidos, pouco valorizados pela crítica e cuja poesia inventiva contrariava as regras poéticas tradicionais.
} 
Em entrevista concedida especialmente a este artigo ${ }^{5}$, Jardel Cavalcanti fala sobre a preocupação do poeta com a parte gráfica de seus livros:

O processo de edição dessas plaquetes obedece aos cuidados com a forma gráfica pré-determinada pelo poeta, sendo essa uma preocupação básica, já que a relação entre palavra e imagem é determinante na sua obra. Ou seja, se há alguma interferência do editor naquilo que Augusto de Campos planeja, ela é mínima, sendo apenas, quando acontece, para se adequar à possibilidade de uma impressão correta nos termos do feitio do livro. (CAVALCANTI, 2021)

A parceria, então, entre editores independentes como Jardel Cavalcanti e o poeta Augusto de Campos se estabelece a partir desse vínculo editorial e literário, em que o último tem liberdade para elaborar a parte gráfica de suas edições e também certo desprendimento em relação a prazos e burocracias editoriais que, embora necessárias, podem se tornar obstáculos atualmente, devido à idade mais avançada de Augusto e à grande demanda por textos e entrevistas.

Nestas publicações mais recentes das plaquetes, o foco tem sido as traduções criativas de Augusto (ou 'transcriações", no termo haroldiano) e não seus poemas autorais inéditos - publicados, com mais frequência, em suas redes sociais. Como o poeta afirma, em entrevista de 2003, o que o interessa especialmente não é a sua própria poesia, mas sim a poesia, "tout court": "gosto do convívio com os outros poetas, os poetas que admiro, e traduzi-los, converter os seus poemas originais, de outros idiomas, em poemas de língua portuguesa, é uma forma de dialogar e aprender, celularmente, com eles" (CAMPOS, 2003).

Essa forma de diálogo realizado através da tradução continua a estimular o poeta a buscar autores, por vezes, menos publicados no Brasil ou, ainda, a fazer traduções criativas, sem abrir mão do sentido literal do texto, que demonstrem a potencialidade inventiva de seus escritores. Quanto à sua própria poesia, Augusto diz que ela passa por um crivo severo de autocrítica e que não sente "compulsão para criála nem pressa em publicá-la" (ibidem).

De todo modo, a produção poética, tradutória e ensaística de Augusto de Campos continua a ser divulgada e publicada, ainda que ultimamente menos em

\footnotetext{
${ }^{5}$ Ver anexo.
} 
meios convencionais e mais em plataformas digitais, sites e revistas online, voltando também a encontrar espaço, como no início de sua atividade poética nos anos 1950, nas edições independentes, que lhe permitem prosseguir. Seu público leitor pode, portanto, acessar as suas obras por diferentes meios, mas o que se mantém, sobretudo, é a potencialidade criativa da verbivocovisualidade de seus escritos.

\section{Considerações finais}

Atualmente, o dinamismo do mercado editorial, ocasionado pelo surgimento de pequenas editoras, pela organização de feiras literárias, e o trabalho até mesmo manual de muitos editores independentes possibilitou, portanto, o aparecimento de novos espaços poéticos, literários e artísticos dentro do cenário cultural brasileiro. Ainda que estes espaços operem "à margem", em relação àquele ocupado pelas grandes editoras, eles oferecem ao leitor novos escritores, outros formatos de leitura (entre zines, revistas e livros com designs gráficos distintos) e uma aproximação maior, em muitos dos casos, com seus autores.

Tal circulação de textos e ideias numa variedade maior de formatos permite, inclusive, que autores que já tenham conquistado mais espaço no mercado editorial, como é o caso de Augusto de Campos, se dediquem a outros projetos - como a tradução dos poetas latinos ou dos poetas "maneiristas" italianos, menos conhecidos - e encontrem um meio para concretizar essas publicações, o que seria, todavia, mais difícil de ser obtido através das grandes editoras.

Os benefícios dessa efervescência da produção editorial independente no país permitiram ao poeta Augusto de Campos colocar em circulação suas "extraduções" (em grande parte inéditas) num formato de plaquete, e permitiram que ele continuasse a ser publicado, mesmo num momento de crise editorial. Sua produção publicada por editoras independentes como a Galileu Edições, e por meio de suas próprias redes sociais, continua a dar voz e visibilidade aos seus poemas, ensaios e traduções, rompendo com os obstáculos impostos pelo mercado editorial.

\section{Anexo: Entrevista com Jardel Dias Cavalcanti (2021)}


- Quais foram, até o momento, as publicações de Augusto de Campos feitas pela Galileu Edições?

A Galileu Edições até o momento publicou os seguintes plaquetes com as traduções de Augusto de Campos: Rimbaud, Sylvia Plath, Mariane Moore, Esses Russos, Latinogramas e Poetas Bizzaros na internet.

\section{- Como começou a relação com o poeta?}

A relação com Augusto de Campos se iniciou após eu enviar-lhe uma tradução feita por mim de um ensaio do pianista Gleen Gould sobre a obra de Anton Webern. Junto ao envio, fiz um convite ao poeta para publicar algo na Galileu Edições imaginando que ele se interessaria em publicar um pequeno volume, seja de sua própria obra poética ou de tradução. Ele prontamente aceitou, me enviando semanas depois sua primeira Extradução (que é como ele denomina as traduções que tem me enviado).

\section{- Como se dá o processo de edição das plaquetes?}

O processo de edição dessas plaquetes obedece aos cuidados com a forma gráfica pré-determinada pelo poeta, sendo essa uma preocupação básica, já que a relação entre palavra e imagem é determinante na sua obra. Ou seja, se há alguma interferência do editor naquilo que Augusto de Campos planeja, ela é mínima, sendo apenas, quando acontece, para se adequar à possibilidade de uma impressão correta nos termos do feitio do livro.

Vezes ou outras, para que nenhuma página fique em branco ao longo da plaquete, acrescento uma imagem do poeta que está sendo traduzido, como foi, por exemplo, o caso dos retratos de Mariane Moore e Maiakovski (criados pelo artista Fabricius Nery). A esses retratos somam-se os já introduzidos pelo próprio Augusto de Campos no livro. Em geral, o poeta trabalha esses retratos graficamente, alterando-os ou fundido a eles intervenções poéticas, ou seja, suas traduções.

Nas primeiras publicações achei que a interferência do nome e da logo da Galileu Edições na capa acabariam por interferir no design estabelecido por Augusto 
de Campos. A pedido de Augusto, acabei nas últimas publicações acrescentando na capa a logo e o nome da Galileu Edições.

\section{- Como é feita a venda de livros pela editora e quantos exemplares são produzidos?}

Quanto ao número de exemplares tenho determinado edições de trinta exemplares cada plaquete, que sendo vendidas ou solicitadas acaba tendo duas ou três edições. Como Augusto de Campos é bem conhecido por seu trabalho inovador e sério, as vendas são rápidas, assim que a divulgamos nas mídias sociais os pedidos aparecem.

Os exemplares são divididos, ficando metade comigo e metade com Augusto. Do dinheiro da venda, posso pagar a impressão e imprimir outras edições e/ou reedições. O valor é de 35 reais, sendo que deste valor 5 reais é para o envio registrado pelo correio para os compradores. Cumpre ressaltar duas coisas: o objetivo da venda dessas edições não é gerar dinheiro, mas capital para a produção de outras edições e publicar poetas que não podem pagar pela editoração de seus livros; outra coisa é que parte desses exemplares é distribuído para pessoas para as quais julgamos importante que as plaquetes cheguem.

Boa parte dos compradores das plaquetes são poetas, professores da área de literatura e escritores em geral. Também pesquisadores da obra de Augusto de Campos, geralmente fazendo mestrado ou doutorado, no Brasil ou no exterior.

\section{Referências}

ADRIANO, Carlos. Augusto de Campos dá vida ao latim em traduções inéditas. Folha de S.Paulo. 21 fev. 2020. Disponível em: $<$ https://www1.folha.uol.com.br/ilustrada/2020/ 02/augusto-de-campos-da-vida-ao-latim-em-traducoes-ineditas.shtml>. Acesso em: 3 dez. 2020.

AGUILAR, Gonzalo. Poesia concreta brasileira: as vanguardas na encruzilhada modernista. São Paulo: Editora da Universidade de São Paulo, 2005.

BAUDELAIRE, Charles. O Albatroz. Tradução: Augusto de Campos. Londrina: Galileu Edições, 2018. 
CAMPOS, Augusto de. À margem da margem. São Paulo: Companhia das Letras, 1989.

; GOMES, Eustáquio; KASSAB, Álvaro. Augusto de Campos. Jornal da Unicamp. Campinas, 24 a 30 de novembro de 2008, ANO XXIII No 417. Disponível em: $<$ https://www.unicamp.br/unicamp/sites/default/files/2017-

12/JU_417_novembro2008_ augusto-campos_20171221.pdf>. Acesso em: 25 fev. 2021.

; CAVALCANTI, Jardel Dias. Entrevista com o poeta Augusto de Campos.

Digestivo Cultural. 24 mar. 2003. Disponível em: $<$ https://www.digestivocultural.com/co

lunistas/coluna.asp?codigo=993\&titulo=Entrevista_com_o_poeta_Augusto_de_Camp os>. Acesso em: 22 fev. 2021.

; CAVALCANTI, Jardel Dias. Entrevista Poesia e Ditadura. Galileu Edições, 2019.

. Latinogramas - Extraduções. Londrina: Galileu Edições, 2019.

. Marianne Moore - 10 Poemas. Londrina: Galileu Edições, 2019.

Outro. São Paulo: Perspectiva, 2015.

PLAZA, Julio. Poemóbiles. São Paulo: Selo Demônio Negro, 2010.

Poesie - Eine Anthologie. Tradução de Simone Homem de Mello. São Paulo: Selo Demônio Negro, 2019.

Poetas Bizarros na Internet - Extraduções. Londrina: Galileu Edições, 2020.

Retrato de Sylvia Plath como Artista. Londrina: Galileu Edições, 2019.

. Rimbaud - Extraduções. Londrina: Galileu Edições, 2019.

; CAMPOS, Haroldo de; PIGNATARI, Décio. Teoria da poesia concreta: textos críticos e manifestos de 1950-1960. Cotia: Ateliê Editorial, 2006.

CAVALCANTI, Jardel Dias. Galileu Edições: entrevista com Jardel Cavalcanti. Revista Abraços Morbos, $2020 . \quad$ Disponível em: $<$ https://samusque.wixsite.com/amorbos/galied >. Acesso em: 3 jan. 2021.

GANDOLFI, Leonardo. Augusto de Campos, 87, dá a cara a tapa no Instagram. 7 de agosto de 2018.2 Disponivel em: $<$ https://www1.folha.uol.com.br/ilustrada/2018/o8/augusto-de-campos-87-da-a-caraa-tapa-no-instagram.shtml>. Acesso em: 1 dez. 2020. 
PIGNATARI, Décio. Poesia pois é poesia: 1950-2000. Cotia, SP: Ateliê Editorial; Campinas, SP: Editora da Unicamp, 2004.

PINTO, Manuel da Costa. A galáxia concreta e o buraco negro da crítica. Folha de S.Paulo. 27 de agosto de 2005. Disponível em: < https://www1.folha.uol.com.br/fsp/ilus trad/fq2708200510.htm>. Acesso em: $30 \mathrm{dez}$. 2020.

VIGNOLI, Flávio. Cleber Teixeira. Disponível em: <http://www.editoranoanoa.com.br/ cleber-teixeira/>. Acesso em: 2 jan. 2021.

\footnotetext{
' É Pós-Doutoranda em Estudos Literários pela Universidade Federal de São Carlos e membro do NEPPOC - Núcleo de Estudos e Pesquisas em Poesia e Cultura, sob a supervisão da Profa. Dra. Diana Junkes. É Doutora e Mestra em Literatura pela Universidade de Brasília. Foi Visiting Assistant of Research em Yale University, EUA. Membro da Brazilian Studies Association (BRASA), graduada em Letras - Português - pela UNB e em Jornalismo pelo Instituto de Educação Superior de Brasília (IESB). Autora de inúmeros artigos em revistas literárias diversas.
} 